\title{
SISTEM AKUAPONIK UNTUK PETERNAKAN LELE DAN TANAMAN KANGKUNG HIDROPONIK BERBASIS IOT DAN SISTEM INFERENSI FUZZY
}

\author{
Fachrul Rozie $^{* 1}$, Iwan Syarif ${ }^{2}$, M. Udin Harun Al Rasyid ${ }^{3}$, Edi Satriyanto ${ }^{4}$ \\ 1,2,3,4 Politeknik Elektronika Negeri Surabaya, Indonesia, ${ }^{1}$ Politeknik Negeri Ketapang, Indonesia \\ Email: ${ }^{1}$ fachrul.rozie@politap.ac.id, ${ }^{2}$ iwanarif@pens.ac.id, ${ }^{3}$ udinharun@pens.ac.id, ${ }^{4}$ edi@pens.ac.id \\ *Penulis Korespondensi
}

(Naskah masuk: 07 September 2020, diterima untuk diterbitkan: 02 Februari 2021)

\begin{abstract}
Abstrak
Akuaponik adalah penggabungan sistem budidaya akuakultur dan hidroponik yang dapat menjadi solusi untuk mengatasi keterbatasan lahan, keterbatasan sumber air serta meningkatkan ketahanan pangan. Pada sistem akuaponik, kualitas air pada budidaya ikan merupakan salah satu syarat utama dalam keberhasilan proses budidaya. Penelitian ini mengkombinasikan peternakan lele dengan penanaman kangkung hidroponik. Kotoran ikan lele dan sisa makanan terakumulasi di air dan dapat menjadi racun bagi ikan lele karena mengandung kadar anomia yang tinggi sehingga sangat berbahaya jika tidak dibuang. Air ini kemudian dialirkan ke tanaman kangkung hidroponik melalui biofilter yang bermanfaat sebagai pengurai air kotor dari kolam menjadi nitrat dan nitrit yang berguna sebagai nutrisi tanaman. Selanjutnya setelah air menjadi bersih dan mempunyai kadar oksigen yang tinggi, air tersebut dialirkan kembali ke kolam ikan lele. Penelitian ini bertujuan untuk mengembangkan sistem cerdas pada budidaya akuaponik dengan memanfaatkan teknologi Internet of Things yang dilengkapi dengan beberapa jenis sensor untuk memantau dan mengendalikan kualitas air dengan menerapkan algoritma Sistem Inferensi Fuzzy / Fuzzy Inference System (FIS) untuk mengatur kecepatan sirkulasi air kolam agar menghemat daya listrik pada pompa. Peralatan ini juga dilengkapi dengan layanan pemberian pakan ikan secara otomatis yang dapat diprogram sesuai kebutuhan. Sistem akuaponik ini dapat dipantau melalui web maupun ponsel pintar berbasis android. Pengujian yang dilakukan terhadap perbandingan keputusan oleh pakar dan sistem FIS pada kecepatan sirkulasi air sistem akuaponik menunjukkan nilai akurasi $83,33 \%$, dan hasil dari pengujian ketepatan alat pemberi pakan yang dibuat secara otomatis terhadap ketepatan pemberian pakan secara manual memiliki nilai akurasi 90,97\%.
\end{abstract}

Kata kunci: Internet of Things, Akuaponik, Sistem Inferensi Fuzzy, Hidroponik

\section{AQUAPONICS SYSTEM FOR CATFISH FARMS AND HYDROPONIC KALE PLANTS BASED ON IOT AND FUZZY INFERENCE SYSTEM}

\begin{abstract}
Aquaponics is a combination of aquaculture and hydroponic cultivation systems that can be a solution to overcoming limited land, limited water sources and increasing food security. In the aquaponics system, water quality in fish farming is one of the main requirements in the success of the cultivation process. This research combines catfish farming with hydroponic kale cultivation. Catfish feces and food scraps accumulate in water and can be toxic to catfish because they contain high levels of anomia so it is very dangerous if not disposed of. This water is then flowed to hydroponic kale plants through a biofilter which is useful as decomposing dirty water from the pond into nitrates and nitrites which are useful as plant nutrients. Furthermore, after the water becomes clean and has high oxygen levels, the water is flowed back into the catfish pond. This study aims to develop a smart system in aquaponic cultivation by utilizing Internet of Things technology which is equipped with several types of sensors to monitor and control water quality by applying the Fuzzy Inference System (FIS) algorithm to regulate the speed of pool water circulation in order to save electric power on the pump. This equipment is also equipped with an automatic fish feeding service which can be programmed as needed. This aquaponics system can be monitored via the web or an Android-based smart phone. Tests carried out on the comparison of decisions by experts and the FIS system on the water circulation speed of the aquaponics system show an accuracy value of $83.33 \%$, and the results of testing the accuracy of the feeder that is made automatically against the accuracy of manual feeding have an accuracy value of $90.97 \%$.
\end{abstract}

Keywords: Internet of Things, aquaponics, Fuzzy Inference System, Hydroponics 


\section{PENDAHULUAN}

Jumlah penduduk Indonesia terus tumbuh dari 261,1 juta jiwa pada 2016 menjadi 263,9 juta jiwa pada 2017. Pada 2018, jumlah penduduk Indonesia mencapai 266,7 juta jiwa. Jumlah penduduk dunia saat ini mencapai 7,7 miliar jiwa (Jayani, 2019). Angka tersebut jelas saja menjadi indikasi semakin meningkatnya jumlah bahan pangan yang harus disediakan. Jika jumlah penduduk tidak diimbangi dengan peningkatan produksi pangan, maka kebutuhan dan ketersediaan pangan tidak dapat dihindari. Isu peningkatan jumlah penduduk dan perubahan iklim global merupakan beberapa faktor yang menjadi tantangan dalam upaya pemenuhan kebutuhan pangan masyarakat. Pemerintah dalam hal ini Kementerian Kelautan Dan Perikanan (KKP) terus mendorong masyarakat dalam produktivitas perikanan Indonesia dan pemerintah terus menggalakkan program agar masyarakat sadar akan sehatnya mengkonsumsi ikan, sebagaimana yang tertuang di dalam regulasi perikanan diantaranya UU No. 31 thn. 2004 tentang Perikanan jo. UU No. 45 thn. 2009 , UU No. 18 tahun 2012 tentang Pangan serta INPRES No. 1 tahun 2017 tentang Gerakan Masyarakat Hidup Sehat (INPRES, 2017). Salah satu yang menjadi perhatian pemerintah adalah sektor Perikanan Budidaya dengan terus mengupayakan pengembangan dan kemajuan pada sektor Perikanan Budidaya ini, sejalan dengan itu menurut sumber Susenas BPS yang diolah Ditjen PDSKKP, data Konsumsi Ikan Nasional Tahun 2012-2017 terlihat semakin meningkat kebutuhan masyarakat untuk mengkonsumsi ikan (KKP, 2019). Termasuk salah satunya ikan lele, sebab itulah harus dibuat sistem pertanian dan perikanan yang mudah diaplikasikan pada lahan terbatas dan sumber air terbatas.

Secara umum, masalah dalam budidaya perikanan dan budidaya pertanian adalah kebutuhan lahan yang luas dan sumber air yang melimpah, sehingga ketersediaan sumber air juga harus menjadi perhatian, sedangkan pada kolam ikan lele, air dari sisa metabolisme dari pakan harus dibuang agar tidak terlalu lama ada di dalam kolam karena akan menjadi zat amonia yang tidak baik untuk ikan lele, dan karena itu juga hampir setiap hari petani tambak harus membuang air mengganti dengan air yang memiliki kualitas baik dengan sebab itulah budidaya lele memerlukan air yang banyak, serta sulitnya petambak dalam memantau parameter kualitas air di dalam sistem yang dimilikinya untuk menjadi bahan evaluasi.

Beberapa penelitian terkait sistem pemantauan dan pengontrolan akuaponik ini juga sudah banyak dilakukan dengan berbagai inovasi seperti, pembuatan sistem akuaponik dengan teknologi IoT dengan mengintegrasikannya pada aplikasi android dan website dengan beberapa pengendalian aktuator (Vernandhes, dkk, 2018), kemudian membuat sistem akuaponik dengan sistem peringatan dini, (Dutta, dkk, 2019), serta mengembangkan sistem yang bisa dipantau dan dikendalikan secara realtime, (Valiente, dkk, 2019), menambahkan sistem pemberian pakan otomatis pada sistem akuaponik, (Ambrosio, dkk, 2019), dan (Butt, dkk, 2019). Dari beberapa penelitian yang ada masih belum dilakukan pengendalian dengan metode tertentu, hanya baru bersifat kendali otomatis on atau off, serta masih berbentuk prototipe.

Penelitian ini mengusulkan metode Sistem Inferensi Fuzzy atau Fuzzy Inference System (FIS) dengan parameter input, yaitu suhu dan amonia yang menjadi parameter pengambilan keputusan pada FIS untuk menghemat daya pada pompa air di sistem akuaponik yang harus menyala 24 jam tanpa mengurangi kualitas air kolam pada sistem akuaponik, kemudian alat pada penelitian ini di implementasikan pada kolam sebenarnya, agar dapat mengatasi masalah-masalah yang ada pada sistem budidaya ikan lele konvensional. Jika biasanya limbah air hanya dibuang, pada sistem akuaponik dimanfaatkan sebagai nutrisi tanaman hidroponik (Sagita, dkk, 2014).

\section{METODE PERANCANGAN}

Semua komponen elektronik dipasang menjadi perangkat dan dirangkai menjadi satu sistem perangkat keras (Hardware), untuk perancangan perangkat lunak (software) dibuat dengan membuat program pengontrol baik pada sistem Internet of Things pada aplikasi web maupun pada sistem mikrokontroler nya. Adapun keseluruhan alur kerja sistem seperti yang ditunjukan pada gambar 1. Ada 4 sistem yang saling terhubung, yaitu; (1). Sistem Pemantauan, (2). Sistem Pemberitahuan Dini, (3). Sistem Kendali Sirkulasi Air, (4). Sistem Pemberi Pakan Otomatis.

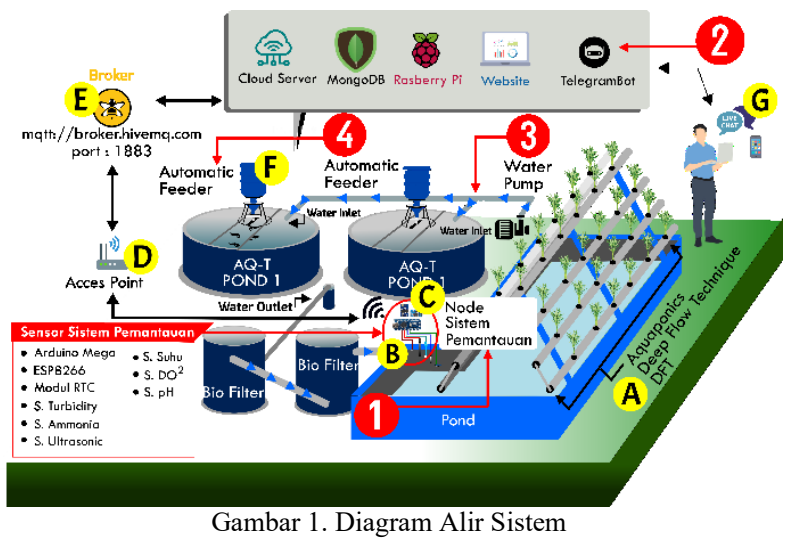

Penjelasan dari sistem teknologi akuaponik yang ditunjukan oleh gambar 1 adalah:

a. Sistem akuaponik dirancang dengan menggunakan desain hidroponik Deep Flow Technique (DFT) dengan menggunakan 2 kolam, dengan menggunakan konsep Biofilter (Sagita et al., 2014).

b. Karena air pada akuaponik terus bersirkulasi sensor akan dipasang pada salah satu kolam, kemudian data hasil sensor akan disimpan dan diolah ke dalam mikrokontroller yaitu Arduino Mega kemudian ditampilkan ke LCD 20x4.

c. Kemudian untuk pengontrolan sirkulasi air ditanam ke dalam mikrokontroller dengan metode FIS mamdani dengan input parameter amonia dan suhu 
dan output keputusan adalah duty cycle, seperti yang ditunjukan pada gambar 5 .

d. Setelah data diolah oleh mikrokontroler dan ditampilkan data ini akan dikirim oleh modul WIFI ESP8266 melalui akses poin ke lokal server yang terpasang yaitu Raspberry Pi dan kemudian disimpan ke dalam database MongoDb sehingga sewaktuwaktu bisa di evaluasi.

e. untuk sistem IoT yang digunakan untuk mengirim data berjalan dengan protokol MQTT hive.mq.com.

f. untuk sistem pemberian pakan ikan otomatis berjalan dengan dasar frekuensi pemberian pakan berdasarkan standar dari Badan Standar Nasional Indonesia (Badan Standar Nasional Indonesia, 2014).

g. Jika terjadi kondisi abnormal sistem mampu memberikan peringatan dini melalui livechat telegram bot.

Perancangan pada perangkat keras terdiri dari 3 bagian yaitu, (1). Pembuatan perangkat pemantau, (2). Membuat Sistem Kendali Sirkulasi Air, (3). Pembuatan alat pakan otomatis, (4).Pembuatan aplikasi web pemantau dan peringatan dini telegram bot.

\subsection{Perancangan dan Implementasi Perangkat Pemantau.}

Perangkat pemantau terdiri dari beberapa komponen yaitu: (1). Sistem Minimum Arduino Mega, (2) Modul WIFI (ESP8266), (3) Sensor Ph (PH-4502C), (4) Sensor Oksigen Terlarut (DO2), (5) Sensor Kekeruhan (Turbidity), (6) Sensor Amonia (MQ-135), (6) Sensor Ultrasonik (HC-SR04), (7) Sensor Suhu (DS18S20), (8) LCD I2C 4x20, (9) AC Light Dimmer dan Zero Crossing (Robodyn), (10) Pompa Air AC 1 Phasa, dengan wiring diagram seperti yang ditunjukan pada gambar 2 .

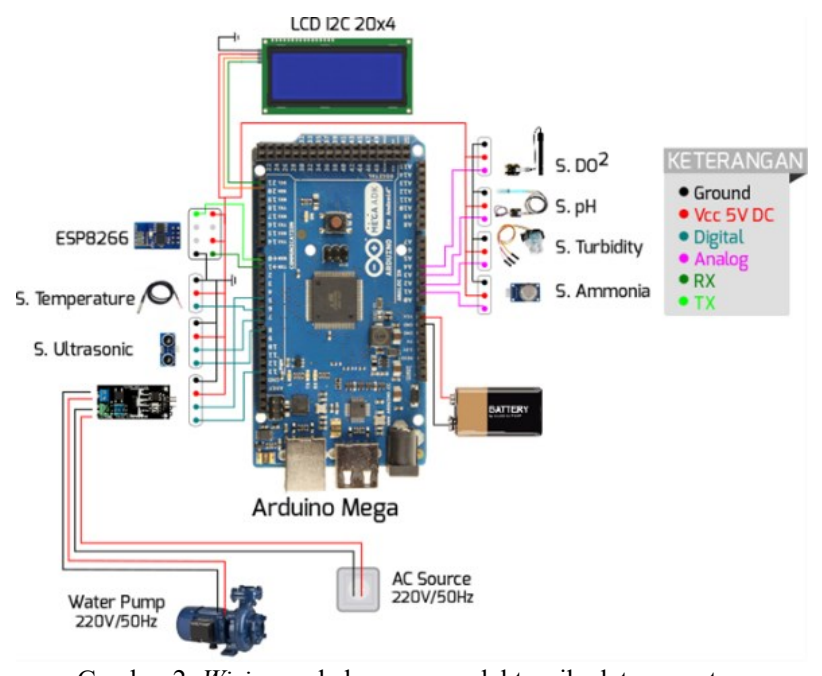

Gambar 2. Wiring pada komponen elektronik alat pemantau

Pengambilan dan pengiriman data di lakukan setiap 15 menit lalu dari beberapa parameter yaitu suhu dan amonia akan diatur oleh kecepatan pompa air.

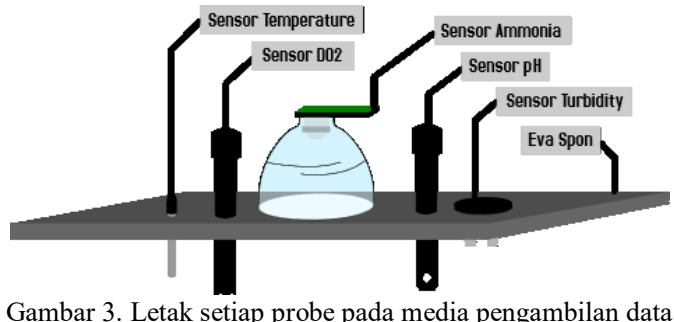

Pada gambar 3, menunjukkan media penempatan sensor di kolam yang dirancang pada sebuah media apung Eva spon yang nanti akan mengapung pada kolam. Gambaran dalam perangkat yang sudah dibuat seperti yang ditunjukkan pada gambar 4 .

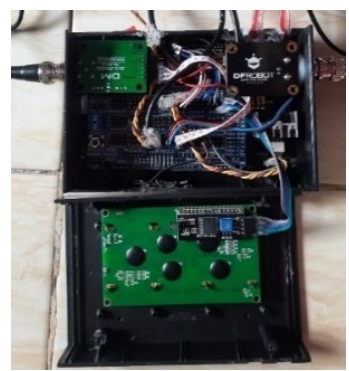

Gambar 4. Tampak dalam komponen perangkat Pemantau

\subsection{Perancangan Pengontrol Sirkulasi Air}

Pada penelitian ini sistem cerdas yang dipakai adalah metode FIS mamdani untuk pengambilan keputusan nilai duty cycle untuk proses sirkulasi airnya, dengan model yang ditunjukkan oleh blok diagram gambar 5.

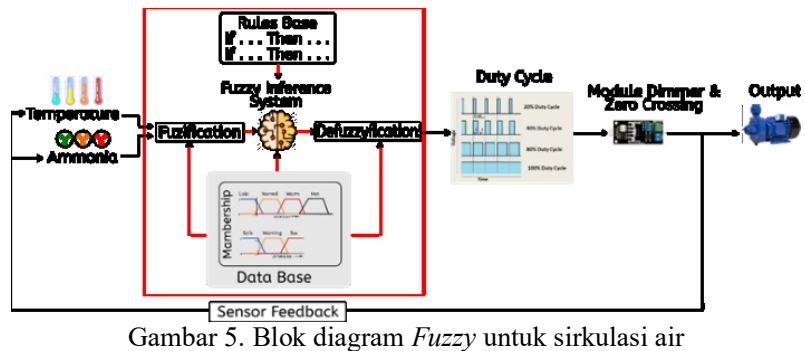

Konsep fuzzy pada penelitian ini, dari variabel input amonia dan suhu, output nya adalah pengambilan keputusan nilai duty cycle yang sudah disesuaikan dengan debit air yang bersirkulasi bisa lambat, sedang, dan cepat sesuai rulebase pada tabel 1, banyak debit air dipengaruhi perubahan duty cycle. pemilihan parameter suhu dan amonia dimana jika nilai amonia tinggi yang dideteksi oleh sensor yang sudah dikalibrasi, dengan konsep logaritmik sesuai datasheet sensor dan penelitian oleh (Nugroho M.A dan Rivai M, 2018), sistem harus membuat pompa air menyirkulasikan total jumlah air pada kolam, menuju ke biofilter dan hidroponik dalam waktu kurang dari satu jam, agar amonia bisa direduksi oleh filter dan tanaman kangkung, sebab amonia yang tinggi dalam waktu singkat akan membunuh ikan, jika amonia dan suhu baik maka pompa bekerja pada debit air normal, atau lambat, agar penggunaan energi listriknya berkurang. Amonia ini berupa kotoran sisa pakan yang 
ada di dalam kolam, bisa juga pengaruh ukuran ikan, suhu dan sebagainya, sehingga air kolam harus disirkulasikan ke dalam filter dan terjadi proses nitrifikasi yang menghilangkan unsur racun pada air, sehingga berganti dengan air yang berkualitas baik seperti proses daur pada gambar 6.

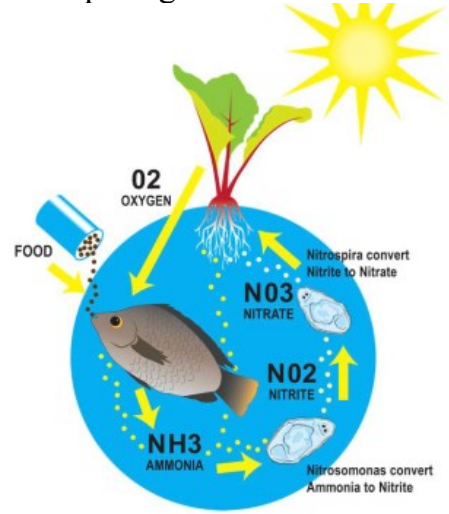

Gambar 6. Daur Siklus Akuaponik (EcolifeAquaponic, 2017)

Dengan pengontrolan motor menggunakan pengaruh dari Dutty Cycle, motor AC ini diharapkan lebih menghemat penggunaan energi pada teknologi akuaponik terutama yang dipakai pada waterpump untuk proses sirkulasi air demi menjaga keberlangsungan hidup dari sistem akuaponik.

Dalam hal ini diperlukan plan yang tepat untuk menjalankan aktuator pada sistem akuaponik. Proses pengumpulan data dalam bentuk pengetahuan yang diperoleh dari para ahli dan standar yang ditetapkan oleh badan standar nasional Indonesia terkait baku mutu kualitas air yang kemudian dipakai sebagai titik acuan pembuatan fungsi keanggotaan sistem inferensi fuzzy. Dari proses wawancara dan studi literatur tersebut dibuatlah fungsi keanggotaan sistem inferensi fuzzy kemudian dibuat proses fuzzyfikasi, implikasi, komposisi, dan Defuzzyfikasi sehingga menghasilkan keluaran keputusan dutty cycle ke pompa air.

\subsubsection{Sistem Fuzyfikasi}

Fuzyfikasi merupakan proses mengolah data input dari sensor Suhu dan Amonia.

\subsubsection{Variabel Suhu}

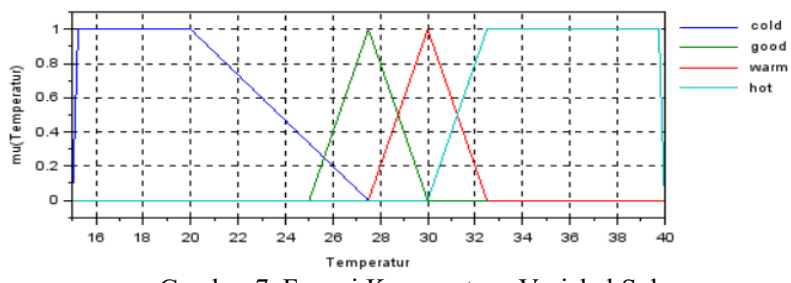

Gambar 7. Fungsi Keanggotaan Variabel Suhu

Variabel fuzzy suhu terdiri atas 4 (Empat) himpunan fuzzy, yaitu dingin (cold), baik (good), hangat (warm) dan panas (hot) seperti yang ditunjukkan pada Gambar 7. Dengan fungsi keanggotaan diselesaikan dengan persamaan (1), (2), (3) dan (4) sebagai berikut:

$$
\begin{aligned}
& \mu_{\text {T.cold }}(x)=\left\{\begin{array}{ccc}
1 & ; & 15 \leq x \leq 20 \\
\frac{27,5-x}{27,5-20} & ; & 20 \leq x \leq 27,5 \\
0 & ; & 27,5 \geq x
\end{array}\right\} \\
& \mu_{T . g o o d}(x)=\left\{\begin{array}{ccc}
\frac{x-25}{27,5-25} & ; & 25 \leq x \leq 27,5 \\
\frac{30-x}{30-27,5} & ; & 27,5 \leq x \leq 30 \\
0 & ; & 30 \geq x
\end{array}\right\} \\
& \mu_{\text {T.warm }}(x)=\left\{\begin{array}{ccc}
\frac{x-27,5}{30-27,5} & ; & 27,5 \leq x \leq 30 \\
\frac{32,5-x}{32,5-30} & ; & 30 \leq x \leq 32,5 \\
0 & ; & 32,5 \geq x
\end{array}\right\} \\
& \mu_{\text {T.hot }}(x)=\left\{\begin{array}{ccc}
\frac{x-30}{32,5-30} & ; & 30 \leq x \leq 32,5 \\
1 & ; & 32,5 \leq x \leq 40 \\
0 & ; & 40 \geq x
\end{array}\right\}
\end{aligned}
$$

\subsubsection{Variabel Amonia}

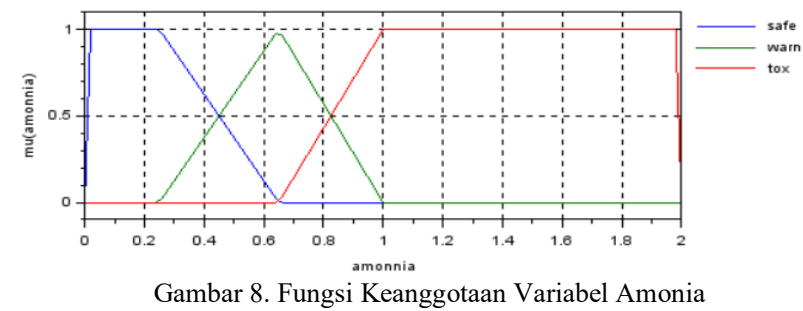

Variabel fuzzy amonia terdiri atas 3 (tiga) himpunan fuzzy, yaitu aman (safe), peringatan (warn), dan beracun (tox) seperti yang terlihat pada Gambar 8 .

Dengan fungsi keanggotaan diselesaikan dengan persamaan (5), (6), dan (7).

$$
\begin{aligned}
& \mu_{\text {a.safe }}(x)=\left\{\begin{array}{ccc}
1 & ; & x \leq 0 \\
\frac{0,65-x}{0,65-0,25} & ; & 0,25 \leq x \leq 0,65 \\
0 & ; & 0,65 \geq x
\end{array}\right\} \\
& \mu_{\text {a.warn }}(x)=\left\{\begin{array}{ccc}
\frac{x-0,25}{0,65-0,25} & ; & 0,25 \leq x \leq 0,65 \\
\frac{1-x}{1-0,65} & ; & 0,65 \leq x \leq 1 \\
0 & ; & 1 \geq x
\end{array}\right\} \\
& \mu_{\text {a.tox }}(x)=\left\{\begin{array}{ccc}
\frac{x-0,65}{1-0,65} & ; & 0,65 \leq x \leq 1 \\
1 & ; & 1 \leq x \leq 2 \\
0 & ; & 2 \geq x
\end{array}\right\}
\end{aligned}
$$

\subsubsection{Variabel Kecepatan Motor}

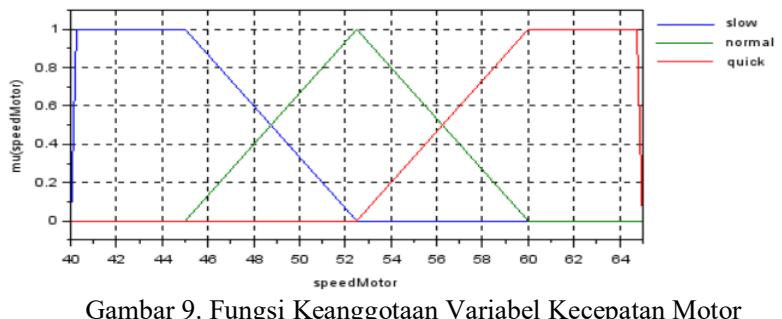

Variabel fuzzy kecepatan motor terdiri atas 3 (tiga) himpunan fuzzy, yaitu lambat (slow), normal (normal), dan cepat (quick) seperti yang ditunjukkan pada Gambar 9.

Dengan fungsi keanggotaan sebagai berikut: 


$$
\begin{aligned}
& \mu_{\text {S.Slow }}(x)=\left\{\begin{array}{ccc}
1 & ; & 40 \leq x \leq 45 \\
\frac{52,5-x}{52,5-45} ; & 45 \leq x \leq 52,5 \\
0 & ; & x \geq 52,5
\end{array}\right\} \\
& \mu_{\text {S.Normal }}(x)=\left\{\begin{array}{ccc}
\frac{x-45}{52,5-45} & ; & 45 \leq x \leq 52,5 \\
\frac{60-x}{60-52,5} & ; & 52,5 \leq x \leq 60 \\
0 & ; & x \geq 60
\end{array}\right\} \\
& \mu_{\text {S.Quick }}(x)=\left\{\begin{array}{ccc}
\frac{x-60}{65-60} ; & 0,65 \leq x \leq 1 \\
1 & ; & 60 \leq x \leq 65 \\
0 & ; & x \geq 65
\end{array}\right\}
\end{aligned}
$$

Setelah semua nilai eror dihitung pada persamaan (8), (9) dan (10) dan kita mendapatkan nilai keanggotaan masukannya di setiap variabel input maka keputusan untuk menggerakkan aerator dengan kecepatan tertentu dapat diproses berdasarkan pada aturan yang ditunjukkan pada tabel 1 .

Tabel 1. Aturan Dasar untuk Sistem Inferensi Fuzzy

\begin{tabular}{cccccc}
\hline \multirow{2}{*}{ Rule } & \multicolumn{4}{c}{ Temperature } \\
\cline { 2 - 5 } & Cold & Good & Warm & Hot \\
\hline \multirow{2}{*}{ Safe } & Slow & Slow & Normal & Quick \\
\cline { 2 - 5 } & Warn & Slow & Normal & Normal & Quick \\
\cline { 2 - 5 } & Tox & Quick & Quick & Quick & Quick \\
\hline
\end{tabular}

Kemudian nilai hasil akhir keputusan tersebut bisa didapatkan dengan proses defuzzyfikasi dari aturan yang telah dibuat. Kemudian didapatlah sebuah keputusan yang berupa duty cycle dan output berupa pengaruh duty cycle terhadap tegangan dan debit air.

\subsection{Perancangan dan Implementasi Perangkat Pakan Otomatis.}

Pada umumnya penelitian untuk membuat alat pakan otomatis sudah banyak diteliti dan dikembangkan, terutama pada kolam budidaya (Yenni dan Benny, 2016), namun yang membedakan adalah metode pemberian pakan yang menyesuaikan dengan kondisi lingkungan.

Komponen sistem pemberi pakan otomatis yang digunakan pada penelitian ini adalah: (1) Modul RTC, (2) Sistem minimum Arduino Nano, (3) Motor DC 12Volt 500RPM, (4) Relay, (5) Sensor Ultrasonik, (6). LCD I2C.

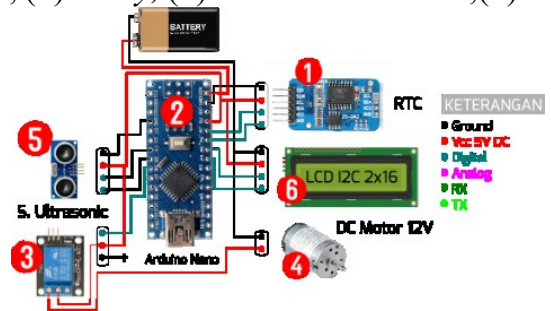

Gambar 10. Wiring pada komponen pemberi pakan otomatis

Gambar 10 adalah wiring yang menghubungkan antara komponen pemberi pakan otomatis, dan penjelasan cara kerjanya adalah: (1). modul RTC akan menentukan waktu realtime pada sistem pakan, (2). Arduino akan memproses dan mengatur waktu pemberian pakan, (3). Arduino mengaktifkan relay sesuai dengan jadwal yang ditentukan, (4). Setelah relay aktif Pakan akan disebar oleh motor DC sesuai dengan jadwal dan lama waktu sebaran, sesuai dengan persamaan (12), (5). Sensor ultrasonik digunakan untuk mengukur sisa jumlah pakan yang ada di dalam wadah pemberian pakan dan, (6). Kemudian data waktu dan pakan ditampilkan pada LCD I2C. Pemberian pakan akan diatur berdasarkan waktu ideal per hari untuk kolam lele yang di sesuaikan dengan berat lele pada persamaan (11)

$T P=5 \% x\left(\sum B x M b\right)$

Keterangan :

$\mathrm{TP}=$ Total pakan per hari

$\sum \mathrm{B}=$ Jumlah Total benih dalam kolam

$\mathrm{Mb}=$ Berat benih per ekor

dan proses kalibrasi dengan persamaan (12)

$T p=20 /\left(\sum p\right)$

Keterangan:

Tp $=$ Waktu Pemberian Pakan

$\sum \mathrm{p}=$ Jumlah Pakan yang Ingin Disebar

Pada gambar 11 menunjukkan hasil perakitan dari perangkat alat pemberi pakan otomatis.

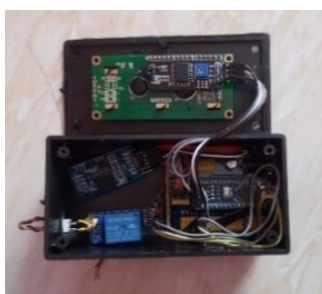

(a)

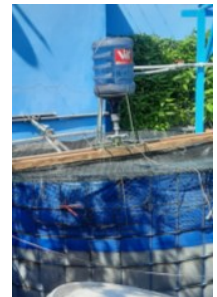

(b)
Gambar 11. (a) Tampak dalam komponen perangkat pemberi pakan otomatis (b) Implementasi wadah pakan di kolam budidaya

\subsection{Perancangan Aplikasi Pemantauan, Notifikasi dan Sistem}

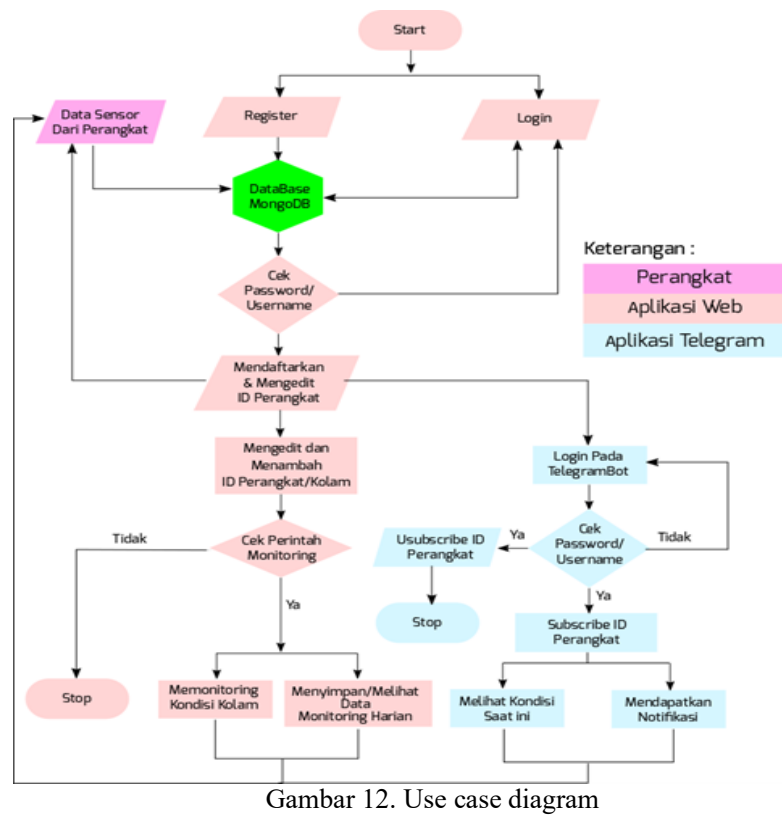


Pada aplikasi web pengguna harus mendaftarkan diri terlebih dahulu, kemudian data diri akan tersimpan ke dalam database MongoDb, kemudian pengguna perangkat mendaftarkan Identitas (ID) perangkat yang dimilikinya, data ID tersimpan pada database dan petambak bisa mengubah ID dan menghapusnya, jika perangkat sudah didaftarkan pengguna bisa melakukan proses pemantauan jika melakukan perintah pemantauan, kemudian setiap proses pemantauan yang dilakukan petambak sistem akan menyimpannya ke dalam database, untuk kemudian suatu saat dilihat dan dievaluasi, yang mana aplikasi ini bisa menyimpannya dalam format PDF, Excel, dan CSV. Pada sisi aplikasi telegram pengguna akan menggunakan username yang telah didaftarkan pada aplikasi web, kemudian harus melakukan subscribe pada ID perangkat yang telah didaftarkan jika ingin memantau. Berikut ini adalah contoh tampilan halaman dashboard dari web aplikasi yang sudah dibuat, data tampil dalam bentuk grafik dan angka, data ini diperoleh dari sistem.

\section{HASIL DAN ANALISIS}

\subsection{Pengujian Kalibrasi Sensor Amonia}

Nilai amonia yang didapat dari sensor MQ-135 merupakan hasil dari nilai pembagi tegangan dari rangkaian ke tegangan sumber yaitu 5 Volt DC, nilai yang dipakai sebagai satuan pada MQ-135 yaitu Part per Million (PPM) (Nugroho \& Rivai, 2018). Pada sensor MQ-135 kemudian kita melihat kembali pada datasheet (Sainsmart, 2013), nilai grafik karakteristik sensitivitas dari sensor MQ-135.

Pada grafik tersebut terdapat perbandingan antara ppm dengan Rs/Ro. Dapat dilihat pada grafik bahwa rasio resistansi fresh air yaitu konstan. Pada pembacaan sensor untuk mendapatkan PPM seluruh hasil perhitungan pada kalibrasi awal dimasukkan ke dalam program dan di inisialisasikan. Pada tabel 3 menunjukkan percobaan pembacaan karakteristik sensor amonia, yang dilakukan dengan mengkondisikan sensor dengan desain tertutup tujuannya agar gas amonia dari air bisa fokus mengalir ke arah sensor, penambahan cairan amonia dilakukan pada sampel 2, 3, dan 4, kemudian untuk sampel 1 pada data yang ditampilkan pada tabel 2 adalah kondisi sebelum penambahan cairan amonia. Sedangkan pada sampel 5 adalah kondisi saat semua cairan sudah dilarutkan dalam waktu tertentu. Dari gambar 13 bisa kita lihat bahwa setiap penambahan cairan, sensor mampu membaca penambahannya, dan kemudian sensor juga mampu membaca penambahan amonia ketika cairan amonia tercampur pada cairan di dalam wadah dimana terlihat pada uji coba sampel 1 dan 5 .

Tabel 2. Penambahan amonia cair pada wadah untuk pengujian karakteristik sensor MQ-135

\begin{tabular}{ccc}
\hline Percobaan & Volume (ml) & PPM \\
\hline 1 & 0 & 0,02 \\
2 & 50 & 0,11 \\
4 & 100 & 0,21 \\
5 & 250 & 0,72 \\
6 & 0 & 0,13 \\
\hline
\end{tabular}

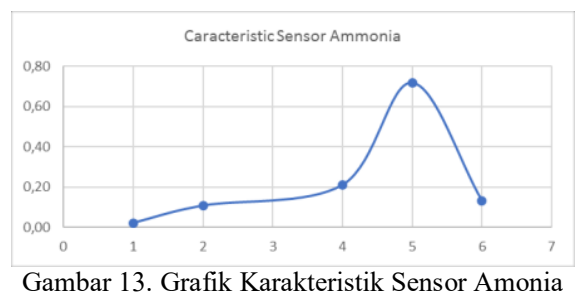

Setelah menguji karakteristik sensor amonia kemudian menghitung nilai kesalahan (eror) pembacaan sensor amonia kemudian membandingkannya dengan tes kit amonia. hasilnya bisa dilihat dengan menghitungnya dengan persamaan (13):

Error $=\frac{\text { Nilai Sebenarnya }- \text { Nilai Sensor }}{\text { Nilai Sebenarnya }} \times 100$

Error $=\frac{0,5-0,45}{0,5} \times 100=10 \%$

Terdapat selisih nilai antara tes kit amonia dan nilai pembacaan sensor MQ-135 yang dihitung dengan membandingkan nilai pembacaan sensor dengan nilai yang diukur dengan tes kit amonia pada air yaitu dengan tingkat kesalahan $10 \%$ seperti yang ditunjukan oleh persamaan (14).

\subsection{Pengujian Sensor Turbidity}

Pengujian pada sensor Turbidity dilakukan dengan Sechi Disk dengan menggunakan sistem regresi linier dengan persamaan yang ditunjukkan oleh persamaan (14) dengan perbandingan Sechie Disk dan nilai ADC dari pembacaan sensor. Nilai regresi linier yang didapat seperti yang ditunjukkan oleh persamaan (15) mewakili gambar grafik pada gambar 17.

$Y=m X+b$

$y=5,171 . X+548,73$

Perlakuan untuk mencari nilai sensor turbidity dengan regresi linier sama dengan persamaan (16), dengan cara mengukurnya dengan menggunakan secchi disk, kemudian membandingkannya dengan nilai ADC sensor seperti yang ditunjukkan oleh tabel 3,

\begin{tabular}{|c|c|}
\hline Secchi Disk (cm) & ADC Sensor \\
\hline 72,5 & 917 \\
\hline 50,75 & 829,53968 \\
\hline 41 & 747,52381 \\
\hline 35,5 & 740,56522 \\
\hline 30 & 697,04762 \\
\hline
\end{tabular}

\subsection{Pengujian Sensor Kadar Keasaman (Ph)}

Pengujian pada sensor Ph dilakukan menggunakan sistem regresi linier dengan cara membandingkan $\mathrm{Ph}$ bufer dan nilai tegangan dari pembacaan sensor seperti yang ditunjukkan tabel 4, dengan rumus matematis yang digunakan regresi linier yang ditunjukkan oleh persamaan (13), Dari pengujian yang dilakukan 
didapatlah persamaan (16) yang mewakili nilai perbandingan $\mathrm{Ph}$ bufer dan Tegangan sensor:

$Y=-5,4263 . X+22.226$

Tabel 4. Pengujian kalibrasi sensor $\mathrm{Ph}$

\begin{tabular}{cc}
\hline Volt & Ph \\
\hline 3,3808 & 4 \\
2,6972 & 7 \\
2,5242 & 9 \\
\hline
\end{tabular}

Tabel 5. Pengujian Nilai Pembacaan Sensor $\mathrm{Ph}$

\begin{tabular}{cccc}
\hline Ph & Nilai Sensor & Selisih & Eror $\mathbf{( \% )}$ \\
\hline 4 & 4,43 & 0,43 & 10,75 \\
7 & 7,79 & 0,79 & 11,29 \\
9 & 8,52 & 0,48 & 5,33 \\
\hline
\end{tabular}

Sensor yang sudah dikalibrasi nilainya dibandingkan dengan nilai $\mathrm{Ph}$ sebenarnya seperti yang ditunjukkan tabel (5), untuk mendapatkan nilai akurasi sensor, dari keluaran sensor ini dihitung dengan persamaan (13) didapat nilai akurasi sensor $\mathrm{Ph}$ rata-rata Eror 9,12\% dengan selisih 0,43-0,79 terhadap $\mathrm{Ph}$ sebenarnya, oleh sebab itu perlunya penambahan banyak contoh perbandingan data pada metode kalibrasi dengan regresi linier ini.

\subsection{Pengujian Sensor Suhu}

Pengujian suhu air juga menggunakan library yang sudah dikembangkan oleh pembuat sensor suhu dibandingkan dengan Termometer dengan selisih nilai dibandingkan dengan rumus eror seperti persamaan (13) dari data yang ditunjukkan oleh tabel 6 , hasil erornya rata-ratanya adalah $1,92 \%$.

\begin{tabular}{cccc}
\multicolumn{4}{c}{ Tabel 6. Pengujian Pembacaan Sensor Suhu } \\
\hline Termometer & Sensor & Selisih & Eror \\
\hline 35 & 34,7 & 0,3 & 0,86 \\
32 & 31,4 & 0,6 & 1,88 \\
32 & 31,8 & 0,2 & 0,63 \\
30 & 29,4 & 0,6 & 2 \\
28 & 27 & 1 & 3,57 \\
26 & 25,8 & 0,2 & 0,80 \\
24 & 23,1 & 0,9 & 3,75 \\
\hline
\end{tabular}

\subsection{Pengujian Sensor DO $^{2}$}

Pengujian sensor $\mathrm{DO}^{2}$ dilakukan dengan proses kalibrasi dengan program kalibrasi yang sudah disediakan oleh pengembang sensor dengan penyesuaian pada suhu air yang diuji.

Karakteristik sensor $\mathrm{DO}^{2}$ diuji dengan 4 proses, yaitu proses pengujian tanpa proses aerasi dan sirkulasi, kemudian proses aerasi, dan setelah itu proses dengan sistem sirkulasi dan penggabungan aerasi dan sirkulasi, hasilnya seperti yang ditunjukkan oleh tabel 7.

\begin{tabular}{cc}
\multicolumn{2}{c}{ Tabel 7. Pengujian Karakteristik Sensor $\mathrm{DO}^{2}$} \\
\hline Pola Perlakuan & Nilai $\mathbf{D O}^{\mathbf{2}}(\mathbf{m g} / \mathbf{l})$ \\
\hline Tanpa Aerasi dan Sirkulasi & 8 \\
Aerasi & 13 \\
Sirkulasi & 13 \\
Dengan Sirkulasi dan Aerasi & 14 \\
\hline
\end{tabular}

Dari tabel 7 Proses pengujian karakteristik sensor pada air tenang yang dimasukkan ke dalam sebuah akuarium tanpa perlakuan aerasi dan sirkulasi, pada proses tersebut didapat hasil $8 \mathrm{mg} / \mathrm{l}$, kemudian pada perlakuan aerasi dan sirkulasi sama-sama $13 \mathrm{mg} / \mathrm{l}$, setelah dikombinasikan hasilnya menunjukkan nilai $14 \mathrm{mg} / 1$, artinya proses sirkulasi dan aerasi dapat menambah nilai oksigen terlarut pada air.

\subsection{Pengujian Pada Sensor Ultrasonik}

Pada pengujian sensor ultrasonik dilakukan dengan membandingkan nilai pembacaan sensor dengan alat ukur jarak, sebanyak 9 data dengan jarak maksimal $100 \mathrm{~cm}$ dan minimal $5 \mathrm{~cm}$, seperti data yang disajikan pada tabel 8 .

\begin{tabular}{ccc}
\multicolumn{3}{c}{ Tabel 8. Pengujian Sensor Ultrasonik } \\
\hline Meteran (cm) & Sensor (cm) & Eror \\
\hline 5 & 4,93 & 1,40 \\
10 & 9,37 & 6,30 \\
15 & 14,22 & 5,20 \\
30 & 27,63 & 7,90 \\
50 & 48,84 & 2,32 \\
70 & 68,71 & 1,84 \\
80 & 78,43 & 1,96 \\
90 & 88,31 & 1,88 \\
100 & 97,01 & 2,99 \\
\hline
\end{tabular}

Pada pengujian alat ini cukup baik dalam pengukurannya, dimana terdapat nilai eror dihitung dengan persamaan (13) sehingga didapat nilai rata-rata eror $6,36 \%$.

\subsection{Pengujian Pada Modul Rangkaian Sensor AC Dimmer \& Zero Crossing}

Bisa dilihat pada tabel 9 dan gambar grafik pada gambar 14, bahwa beban atau motor hanya bekerja pada duty cycle 47 - 69\% dan dengan tegangan 138 - 176 volt, maka ini yang nantinya menjadi acuan pembuatan model pada fungsi keanggotaan fuzzy kecepatan motor.

Tabel 9. Pengujian Tegangan dan Daya Kerja Pada Modul Rangkaian AC Dimmer \& Zero Crossing

\begin{tabular}{cccc}
\hline $\begin{array}{c}\text { Duty } \\
\text { Cycle }\end{array}$ & $\begin{array}{c}\text { Tegangan } \\
\text { (Volt) }\end{array}$ & $\begin{array}{c}\text { Daya } \\
\text { (Watt) }\end{array}$ & $\begin{array}{c}\text { Debit Air } \\
\text { (L/Min) }\end{array}$ \\
\hline 10 & 19 & 0 & 0 \\
20 & 51 & 0 & 0 \\
30 & 51 & 0 & 0 \\
35 & 131 & 104,8 & 0,9 \\
40 & 150 & 120 & 5,5 \\
45 & 156 & 124,8 & 8,6 \\
50 & 170 & 136 & 10,6 \\
55 & 175 & 140 & 11,99 \\
60 & 180 & 144 & 12,65 \\
65 & 186 & 148,8 & 13,10 \\
70 & 187 & 149,6 & 13,54 \\
75 & 190 & 152 & 13,76 \\
80 & 200 & 160 & 13,99 \\
85 & 210 & 168 & 13,99 \\
90 & 215 & 172 & 13,99 \\
95 & 220 & 176 & 13,99 \\
96 & 0 & 0 & 0 \\
99 & 0 & 0 & 0 \\
\hline
\end{tabular}




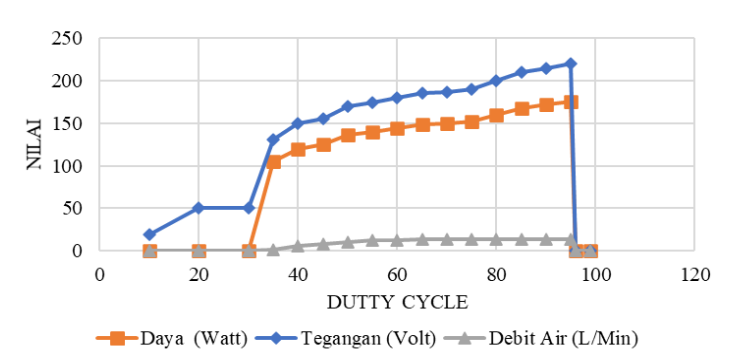

Gambar 14. Pengujian Tegangan Kerja Pada Rangkaian AC Dimmer \& Zero Crossing

Perbedaan debit air tidak memiliki nilai yang signifikan pada masing-masing tegangan kerja karena pengujian dilakukan dengan pompa air akuarium yang memang memiliki tegangan kerja yang rendah.

\subsection{Pengujian Penggunaan Daya Pada Pompa Air sistem akuaponik}

Pada pengujian ini dilakukan perhitungan penggunaan daya listrik pada pompa air pada sistem akuaponik dengan membandingkan penggunaan pompa air dengan sistem pengendalian FIS dan tanpa pengendalian, yang mana nilai daya ini menjadi tolak ukur seberapa efektif untuk mengurangi biaya produksi terutama pada konsumsi energi listrik sebab pompa air pada sistem akuaponik akan bekerja selama 24 jam, dengan menghitung rata-rata penggunaan daya listrik setiap hari seperti yang di tunjukan pada tabel 10 .

Tabel 10. Pengujian Penggunaan Daya Selama 24 jam 1 minggu

\begin{tabular}{ccc}
\hline \multirow{2}{*}{ Hari Ke- } & \multicolumn{2}{c}{ Rata - Rata Penggunaan Daya (Watt) } \\
\cline { 2 - 3 } Tanpa FIS & Dengan FIS \\
\hline 1 & 175 & 136 \\
2 & 175 & 140 \\
3 & 175 & 124,8 \\
4 & 175 & 124,8 \\
5 & 175 & 140 \\
6 & 175 & 140 \\
7 & 175 & 136 \\
\hline Rata - Rata & 175 & 134,5 \\
\hline
\end{tabular}

Untuk nilai Daya dihitung berdasarkan perkalian tegangan dan arus, dengan hasil yang disajikan pada tabel 10 bisa dilihat daya rata-rata yang berkurang setelah melakukan pengendalian dengan metode FIS adalah 40,5 watt. Untuk arus sangat bergantung dengan nilai beban, karena bebannya pada penelitian ini adalah air maka setelah dihitung nilai rata-ratanya adalah 0,8 Ampere, Artinya dari tabel 4 bisa dihitung perbedaan biaya produksi untuk penggunaan pompa air antara pompa yang di kendalikan dengan FIS dan tidak, yang dihitung berdasarkan Tarif Dasar Listrik (TDL) selama 24 jam dalam 30 hari, dengan menggunakan persamaan (17).

$\sum \mathrm{P}=\frac{\bar{P} \cdot 720}{1000} \cdot T D L$

$\sum \mathrm{P}=\frac{134,5 \times 720}{1000} \times 1444,70=139.836$

Jika dihitung dengan persamaan (17) maka didapat nilai total biaya energi listrik untuk pompa air yang dikendalikan dengan FIS adalah sebesar Rp. 139.836, dan untuk yang tidak dikendalikan sebesar Rp. 181.944, artinya biaya listrik pompa air yang dikendalikan dengan FIS lebih hemat Rp. 42.108. Dalam jangka panjang nilai tersebut sangat berpengaruh terhadap biaya produksi.

\subsection{Pengujian Fitur Pemantauan}

Pada pengujian monitoring antara nilai yang tampil pada LCD dengan yang tampil pada web server hampir tidak memiliki waktu tunda, karena inilah kelebihan dari protokol MQTT. Pada gambar 15 menunjukkan hasil dari tampilan halaman dashboard pada penelitian ini, dimana masing-masing parameter bisa dilihat dengan jelas baik grafik dan nilainya.

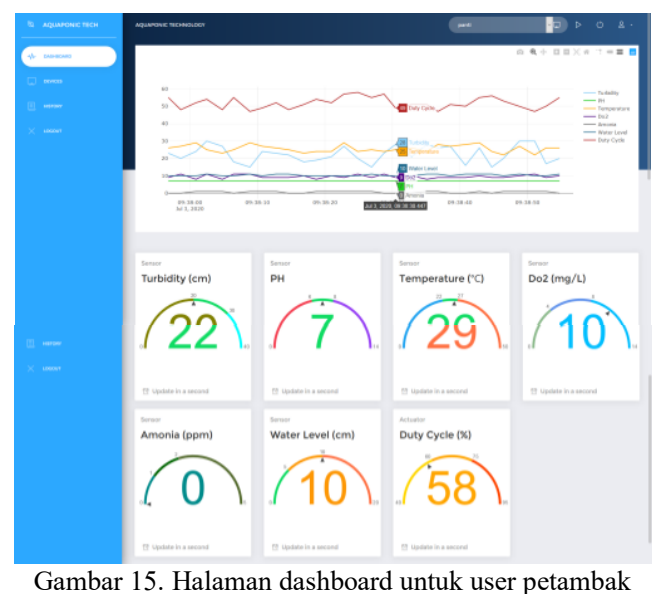

Pada gambar 16 menunjukkan aplikasi telegram bot, yang bisa melakukan pemantauan dan sekaligus juga bisa mendapatkan pemberitahuan jika terjadi sesuatu nilai parameter kualitas air yang abnormal.

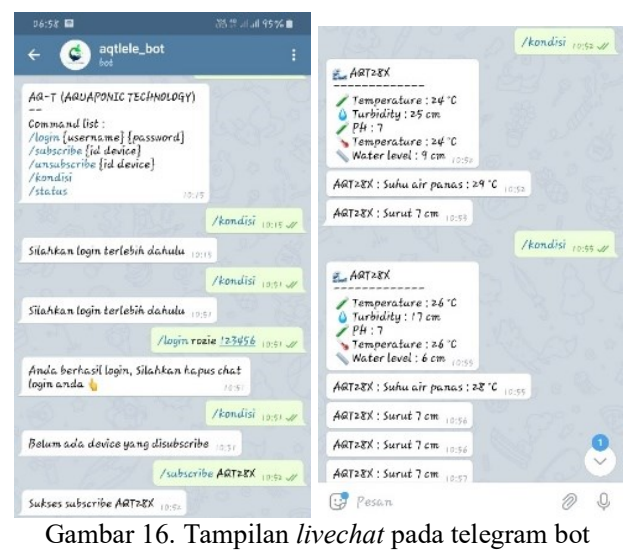

\subsection{Pengujian Fitur Notifikasi}

Untuk pada fitur notifikasi terdapat waktu tunda sekitar 3 detik, hal ini disebabkan oleh proses yang dilakukan pada server telegram sendiri yang merupakan pihak ketiga dan memiliki pengguna aktif lainnya yang menggunakan layanan ini.

\subsection{Pengujian Akurasi FIS Pada Sistem}

Pada percobaan ini percobaan dilakukan dengan membandingkan nilai pakar dan nilai hasil perhitungan 
FIS pada mikrokontroler yang telah dibuat, data hasil pengujian seperti yang ditunjukkan oleh tabel 11.

Tabel 11. Pengujian Akurasi FIS

\begin{tabular}{cccccc}
\hline \multicolumn{2}{c}{ Parameter } & \multicolumn{4}{c}{ Hasil } \\
\hline $\begin{array}{c}\mathbf{A M} \\
\mathbf{M g} / \mathbf{L})\end{array}$ & $\begin{array}{c}\text { SH } \\
\left({ }^{\circ} \mathbf{C}\right)\end{array}$ & Pakar & $\begin{array}{c}\text { DC } \\
\mathbf{( \% )}\end{array}$ & MK & Akurasi \\
\hline 0,01 & 32 & Cepat & 54,78 & Cepat & 1 \\
0,2 & 31 & Normal & 52,48 & Normal & 1 \\
1 & 30 & Cepat & 56,05 & Cepat & 1 \\
0,5 & 29 & Normal & 47,63 & Normal & 1 \\
0,6 & 28 & Cepat & 49.13 & Normal & 0 \\
0,07 & 27 & Lambat & 44,15 & Lambat & 1 \\
1 & 26 & Cepat & 55,42 & Cepat & 1 \\
1 & 25 & Cepat & 55,34 & Cepat & 1 \\
0,4 & 26 & Normal & 46,99 & Normal & 1 \\
0,5 & 27 & Normal & 47,66 & Normal & 1 \\
0,05 & 28 & Normal & 45,22 & Normal & 1 \\
0,6 & 29 & Cepat & 49.03 & Normal & 0 \\
0,3 & 30 & Cepat & 50 & Normal & 0 \\
1,2 & 31 & Cepat & 55,64 & Cepat & 1 \\
0,1 & 32 & Cepat & 54,77 & Cepat & 1 \\
0,8 & 33 & Cepat & 55,61 & Cepat & 1 \\
0,02 & 26 & Lambat & 44,58 & Lambat & 1 \\
0,2 & 29 & Normal & 47,52 & Normal & 1 \\
\hline
\end{tabular}

Keterangan :

(1) AM : Amonia, (2) SH : Suhu, (3) DC : Duty Cycle, (3) MK :Mikrokontroler

Dari data yang ditunjukkan oleh tabel 10, dilakukan pengujian akurasi dengan 18 data dengan 2 input parameter dan 1 output parameter, kemudian dihitung dengan persamaan 18 .

$N A=\frac{\sum(\text { Data Akurat })}{\sum(\text { Seluruh Data })} \times 100 \%$

$N A=\frac{15}{18} \times 100 \%=83,33 \%$

Berdasarkan persamaan 16 hasil perbandingan penilaian pakar dan fuzzy Mamdani dengan 18 data menunjukkan tingkat akurasi $83,33 \%$ dengan predikat keberhasilan yang baik.

\subsection{Pengujian Sistem Sirkulasi Akuaponik}

Pada percobaan sistem, pompa air dipasang di sebuah wadah dengan jumlah air kurang lebih 10 liter, kemudian dilakukan percobaan dengan menyirkulasikan air dengan metode fuzzy dan tidak dalam waktu 2 jam dan dengan sampel data yang diambil adalah 273 sampel dengan pengiriman rata-rata 20 detik per-data, hasilnya suhu air yang disirkulasikan mengalami penurunan suhu signifikan dibandingkan air yang tidak disirkulasikan, bahkan air yang tidak disirkulasikan perlu waktu yang sangat lama untuk mencapai suhu $30^{\circ} \mathrm{C}$, pada percobaan terhitung kurang lebih perlu 3 jam 30 menit sedangkan jika disirkulasi hanya perlu waktu tidak sampai 2 jam, seperti yang bisa dilihat pada gambar 17. Artinya proses sirkulasi sangat berperan penting dalam menjaga kestabilan suhu pada air kolam, sehingga tidak menyebabkan perubahan yang ekstrim pada sebuah kolam sehingga mempengaruhi parameter lainya.

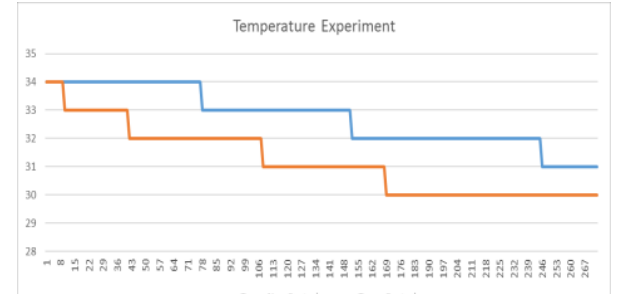

Gambar 17. Grafik perbandingan suhu air yang bersirkulasi dan tidak

Untuk percobaan pada variabel amonia dengan cara menambahkan amonia cair secara bertahap ke dalam wadah berisi air, kemudian menghidupkan pompa air dari sistem akuaponik teknologi seperti yang terlihat pada gambar 18. Terjadi penurunan nilai amonia secara bertahap pada wadah.

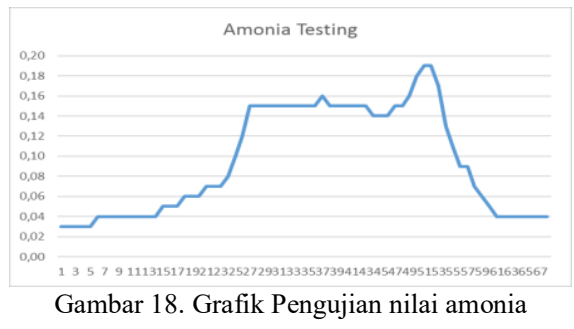

\subsection{Pengujian Alat Pakan}

Dalam 1 Hari setiap kolam akan diberi makan sebanyak $1,5 \mathrm{Kg}$ atau $1500 \mathrm{~g}$ dalam frekuensi 3 kali sehari dalam 1 kali frekuensi akan di berikan pakan pada kolam sebanyak $0,5 \mathrm{Kg}$ atau $500 \mathrm{~g}$ dan dibagi menjadi 3 kali proses jeda yaitu setiap 10 detik. Alat pakan diuji dengan menghitung seberapa ketepatan alat pakan yang dibuat dalam menebarkan pakan pada kolam sesuai dengan jumlah pakan yang biasa dilakukan oleh petambak setiap harinya yaitu $1,5 \mathrm{Kg}$. Pengujian dilakukan selama 7 hari, seperti data yang disajikan dalam tabel 12, data eror menunjukkan seberapa akurasi alat memberikan pakan nilai eror didapat dengan menggunakan persamaan (13).

Tabel 12. Pengujian Pemberian Pakan dengan Alat

\begin{tabular}{cccccc}
\hline Hari & \multicolumn{3}{c}{ Pakan Tiap Frekuensi } & Total & Eror (\%) \\
\cline { 2 - 4 } Ke- & $\mathbf{1}$ & $\mathbf{2}$ & $\mathbf{3}$ & \\
\hline $\mathbf{1}$ & 460 & 478 & 420 & 1358 & 9,47 \\
$\mathbf{2}$ & 456 & 457 & 480 & 1393 & 7,13 \\
$\mathbf{3}$ & 395 & 489 & 424 & 1308 & 12,8 \\
$\mathbf{4}$ & 468 & 467 & 367 & 1302 & 13,2 \\
$\mathbf{5}$ & 487 & 464 & 453 & 1404 & 6,4 \\
$\mathbf{6}$ & 457 & 468 & 490 & 1415 & 5,67 \\
$\mathbf{7}$ & 486 & 423 & 462 & 1371 & 8,6 \\
\hline
\end{tabular}

Dari data yang disajikan pada tabel 12 didapat nilai eror rata-rata selama 7 hari adalah $9,03 \%$, artinya alat dapat berfungsi dengan baik dengan akurasi 90,97\%, dengan data akurasi ini bisa dilakukan proses kalibrasi ulang dan penyesuaian terhadap lama waktu pemberian pakan.

\subsection{Implementasi Sistem Akuaponik}

Pada implementasi sistem, perangkat dipasang dengan masing-masing jarak kurang lebih 1 (satu) meter dari kolam ikan dan dari tanaman. Alat ini juga mampu 
berjalan dengan baik dengan menunjukkan keberhasilan pada panen ikan dan sayur kangkung, seperti yang terlihat pada gambar 19, Pertumbuhan kangkung yang dihasilkan dengan akuaponik tumbuh dengan baik dengan rata-rata penambahan lebar daun $22 \mathrm{~cm}$ dan jumlah cabang 8 dalam waktu 15 hari, Pertumbuhan ikan lele pada sistem akuaponik bisa dipanen dalam waktu yang relatif sama dengan cara konvensional dengan bobot yang juga relatif sama.

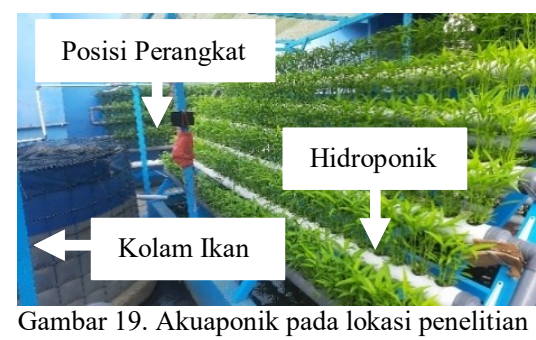

\section{KESIMPULAN}

Sistem akuaponik yang dikembangkan ini menggabungkan sistem pemantauan dan pengaturan ke dalam satu perangkat aplikasi yang memanfaatkan teknologi Internet of Things dan FIS. Dengan perangkat ini, pembudidaya dapat memantau parameter suhu, amonia, tingkat keasaman, tingkat kekeruhan (turbidity), kadar oksigen terlarut (dissolved oxygen) serta tingkat ketinggian air dari kolam ikan lele dan tanaman hidroponik setiap saat baik melalui web maupun ponsel. Sistem ini juga dilengkapi dengan layanan pemberian pakan ikan secara otomatis dan juga layanan deteksi dini jika terjadi permasalahan yang membahayakan kesehatan ikan.

Secara keseluruhan sistem berfungsi dengan baik dimana sistem FIS dari parameter suhu dan amonia untuk pengambilan keputusan nilai duty cycle pada kecepatan motor pompa air memiliki akurasi 83,33\% dengan skema pengujian membandingkan hasil keputusan pakar dengan hasil keputusan sistem FIS pada mikrokontroler. Selain itu penerapan metode FIS pada pengendalian sirkulasi air selain mampu menjaga kualitas air juga berhasil menghemat penggunaan energi listrik rata-rata sebesar 40,5watt dan alat pakan dengan menggunakan sistem otomatis terjadwal memiliki akurasi 90,97\% keberhasilan setelah diuji selama 7 hari dengan skema pengujian membandingkan akurasi jumlah pakan yang disebar manual oleh petambak dengan alat pakan otomatis terjadwal. Hasil pembacaan sensor pada akuaponik ini diteruskan ke web server, kemudian ditampilkan pada aplikasi web maupun telegram bot.

\section{DAFTAR PUSTAKA}

AMBROSIO, A. Z. M. H., JACOB, L. H. M., RULlODA, L. A. R., JOSE, J. A. C., BANDALA, A. A., SY, A., VICERRA, R. R., \& DADIOS, E. P. (2019). Implementation of a Closed Loop Control System for the Automation of an Aquaponic System for Urban Setting. 2019 IEEE 11th International Conference on Humanoid,
Nanotechnology, Information Technology, Communication and Control, Environment, and Management, HNICEM 2019.

BADAN STANDAR NASIONAL INDONESIA. (2014). Bagian 3 : Produksi induk.

BUTT, M. F. U., YAQUB, R., HAMMAD, M., AHSEN, M., ANSIR, M., \& ZAMIR, N. (2019). Implementation of Aquaponics Within IoT Framework. Conference Proceedings - IEEE SOUTHEASTCON, 2019-April, pp.1-6.

DUTTA, A., DAHAL, P., PRAJAPATI, R., TAMANG, P., \& SABAN KUMAR K. C, E. (2019). IoT based Aquaponics Monitoring System. September 2018.

ECOLIFEAQUAPONIC. (2017). Introduction to Aquaponic. Nursing Times, 350, pp.1-24.

INPRES. (2017). Peraturan Presiden Republik Indonesia Nomor 1 Tahun 2017 Tentang Gerakan Masyarakat Hidup Sehat.

JAYANI, D. H. (2019). Jumlah Penduduk Indonesia 269 Juta Jiwa, Terbesar Keempat di Dunia | Databoks. Katadata.Co.Id, 2018. $<$ https://databoks.katadata.co.id/datapublish/2019/ 04/29/jumlah-penduduk-indonesia-269-juta-jiwaterbesar-keempat-dunia> [Diakses 2 Mei 2020]

KKP. (2019). Refleksi Outlook. 67.

NUGROHO, M. A., \& RIVAI, M. (2018). Sistem Kontrol dan Monitoring Kadar Amonia untuk Budidaya Ikan yang Diimplementasi pada Raspberry Pi 3B. Jurnal Teknik ITS, 7(2).

SAGITA, A., WICAKSANA, S. N., PRIMASAPUTRI, N. R., PRAKOSO, K., AFIFAH, F. N., NUGRAHA, A., \& HASTUTI, S. (2014). Pengembangan Teknologi Akuakultur Biofilter Akuaponik (Integrating Fish And Plant Culture) Sebagai Upaya Mewujudkan Rumah Tangga Tahan Pangan Development. Seminar Nasional Tahunan Ke-IV Hasil-Hasil Penelitian Perikanan Dan Kelautan, December 2017, pp.353-361.

SAINSMART. (2013). Tecnical Data Mq-135 Gas Sensor. 1, pp.3-4.

VALIENTE, F. L., GARCIA, R. G., DOMINGO, E. J. A., ESTANTE, S. M. T., OCHAVES, E. J. L., VILLANUEVA, J. C. C., \& BALBIN, J. R. (2019). Internet of things (IOT)-based mobile application for monitoring of automated aquaponics system. 2018 IEEE 10th International Conference on Humanoid, Nanotechnology, Information Technology, Communication and Control, Environment and Management, HNICEM 2018, pp. 1-6.

VERNANDHES, W., SALAHUDDIN, N. S., KOWANDA, A., \& SARI, S. P. (2018). Smart aquaponic with monitoring and control system based on IoT. Proceedings of the 2nd International Conference on Informatics and Computing, ICIC 2017, 2018-Janua(November), pp.1-6.

YENNI, H., \& BENNY. (2016). Perangkat Pemberi Pakan Otomatis pada Kolam Budidaya. Jurnal Ilmiah Media Processor, Oktober 2016. 